\title{
PENGEMBANGAN PROTOKOL PENGKAJIAN SIRKULASI KAKI PADA PASIEN DIABETES MELITUS
}

\author{
Bayu Azhar*, Dewi Elizadiani Suza, Yesi Ariani \\ Fakultas Keperawatan, Universitas Sumatra Utara \\ *bayuazhar05@gmail.com
}

\begin{abstract}
Abstrak
Kaki diabetik merupakan komplikasi akibat gangguan sirkulasi dan neuropati. Pasien diabetes melitus memiliki resiko mengalami gangguan penyakit arteri perifer merupakan komplikasi makrovaskuler dan mikrovaskuler mengakibatkan terganggunya sirkulasi pembuluh darah. Diagnostik awal dapat melakukan pemeriksaan pengkajian sirkulasi kaki pasien diabetes. Tujuan penelitian yaitu pengembangan protokol pengkajian sirkulasi kaki pasien diabetes mellitus. Desain penelitian menggunakan action reseach yang dilakukan satu siklus di Rumah Sakit Umum Mitra Medika Tanjung Mulia Medan, dengan teknik purposive sampling. Instrumen penelitian in-depth interview, focus grup discussion, kuesioner pengetahuan perawat tentang pengkajian sirkulasi kaki pasien diabetes melitus. Partisipan terdiri dari 45 perawat ruangan. Hasil penelitian menghasilkan 4 tema: 1) Strategi penerapan protokol pengkajian sirkulasi kaki pasien diabetes melitus, 2) Manfaat dalam penerapan protokol pengkajian sirkulasi kaki pasien diabetes melitus, 3) Hambatan dalam penerapan protokol pengkajian sirkulasi kaki pasien diabetes melitus, dan 4) Teknik dan penerapan protokol pengkajian sirkulasi kaki pasien diabetes melitus. Hasil analisis kuantitatif tingkat pengetahuan perawat sebelum kegiatan penelitian $86,66 \%$, dan meningkat menjadi $100 \%$ setelah kegiatan penelitian. Direkomendasikan pelaksanaan pengkajian sirkulasi kaki pasien diabetes melitus sesuai standar prosedur sehingga dapat mengidentifikasi sirkulasi kaki pasien diabetes melitus, memperbaiki kualitas pelayanan keperawatan, meningkatkan kompetensi perawat.
\end{abstract}

Kata kunci: Protokol, pengkajian sirkulasi kaki, diabetes melitus

\begin{abstract}
Development of protocol assessment of feet circulation in diabetes melitus patients. Diabetic foot is complication caused by circulation disorder and neuropathy in patients who have the risk for peripheral artery disease which is the complication of macro-vascular and micro-vascular which can eventually cause the incidence of circulation disorder in blood vessels. Initial diagnostic can be done to prevent peripheral artery disease by using circulation studying examination on the feet of diabetic patients. Therefore, it's necessary to develop studying protocol of foot circulation in diabetes mellitus patients at Mitra Medika Hospital, Medan. The research instrument was interviews, in-depth interviews, guidance for focus group discussion, self-report of nurses' knowledge of studying on foot circulation diabetic patients. Participants from 45 nurse practitioners, taken by using purposive sampling technique. The data were analyzed qualitatively and quantitatively. Qualitative data were analyzed by using content analysis while quantitative data were analyzed by using descriptive statistic test. The result of the research showed that 4 themes: 1) strategy of implementing studying protocol of foot circulation diabetes mellitus patients, 2) the benefit of studying protocol of foot circulation diabetes mellitus patients, 3) obstacles in studying protocol of foot circulation diabetes mellitus patients, and 4) technique and implementation of studying protocol of foot circulation diabetes mellitus patients. The result of quantitative analysis showed that nurses' knowledge in pre-research of was $86.66 \%$ and increased to $100 \%$ in post research activity. The output of this research result was the standard of studying foot circulation diabetes mellitus patients. It's recommended the implementation of studying foot circulation accordance with the standard of procedure so that it can identify diabetes mellitus patients' foot circulation, nursing care quality should be improved, and nurses' competence should be increased.
\end{abstract}

Keywords: protocol, assessment of foot circulation, diabetes mellitus

\section{Pendahuluan}

Diabetes mellitus merupakan penyakit kronis yang kompleks yang memerlukan perawatan yang intens dengan mengurangi faktor selain dari pengendalian gula darah (Diabetes Care, 2018). Banyak di temukan komplikasi dari penyakit ini salah satu penyebab utama penyakit kronis 
dan menyebabkan kecacatan, kehilangan anggota tubuh diseluruh dunia (Hingorani et al., 2016). Menurut American Diabetes Association (ADA, 2016), Indonesia merupakan salah satu negara yang penduduk terbanyak menderita DM. International Diabetes Ferderation (2017) menyebutkan bahwa Indonesia saat berada diposisi keenam terbanyak penderita DM di dunia dengan jumlah sebanyak 10,3 juta jiwa dan diprediksi akan naik pada posisi urutan ke 6 pada tahun 2040 dengan jumlah sebanyak 16,2 juta jiwa. Hasil temunan Riset Kesehatan Dasar bahwa pada tahun 2018 terjadi peningkatan $(8.5 \%)$ kejadian diabetes melitus dibandingkan pada tahun 2013 (6.9\%) Kejadian penyakit DM di Provinsi Sumatra Utara mengalamai peningkatan dari $1.7 \%$ pada tahun 2013 meningkat menjadi 2,0\% pada tahun 2018 jumlah ini sama dengan prevalensi kejadian nasional (Riskesdas, 2018).

Meningkatnya kejadian diabetes melitus menyebabkan peningkatan kebutuhan layananan kesehatan oleh pasien DM, upaya untuk menurunkan prevalensi dengan menekan prevalensi, menekan lajunya prehospitalisasi dengan cara mengoptimalkan serta meningkatkan status kesehatan, merubah gaya hidup dan melakukan pencegahan terhadap terjadinya komplikasi dari DM tersebut (Asif, 2014). Jhonson et al. (2017) menyebutkan bahwa komplikasi kaki penyebab utama pada pasien diabetes melitus dan memberikan kontribusi terjadinya peningkatan biaya kesehatan dan perawatan. Penderita diabetes berisiko memiliki gangguan neuropati perifer, penyakit arteri perifer dan infeksi menyebakan amputasi pada bagian ekstremitas pasien diabetes melitus (Yusuf et al., 2016). Terlambatnya diagnostik awal dapat meningkatkan resiko komplikasi yang sangat serius termasuk kecacatan dan amputasi (Shrikhande \& Mckisney, 2012). Penelitian yang dilakukan Ren et al. (2014). Tentang pencegahan komplikasi didapatkan hasil bahwa perawat memiliki peran yang sangat besar untuk memberikan informasi bahwa dengan edukasi sangat efektif bagi perawat untuk mecegah komplikasi pada pasien DM.

Wade (2017) menyebutkan penting dilakukan identifikasi kaki pada pasien diabetes sebagai langkah awal untuk mengetahui masalah yang sering terjadi pada pasein diabetes melitus. Diagnostik dini sangat penting untuk menilai dan mecegah dari komplikasi dari pasien DM. Untuk menilai terjadinya penyakit kardiovaskuler, dapat dilakukan dengan tindakan invasif dan non invasif. Pengukuran invasif dapat dilakukan dengan venography dan angiografi yang dapat dilakukan khusus pada pasien yang akan dilakukan tindakan intervensi lebih lanjut. Pengukuran non invasif dapat melakukan pengukuran transcutaneus oksigen $\left(\mathrm{tcPO} \mathrm{P}_{2}\right)$, doppler vaskuler untuk menilai ankle bracial index (ABI) sirkulasi pembuluh darah arteri dan vena, selain itu dopler juga digunakan untuk mengukur toe bracial index (TBI) (Azzolin, Maggi, Goldmeier, \& Quadros, 2014; Cerville, 2012).

ABI berfungsi sebagai pengukuran aterosklerosis sistemik dan dengan demikian berkaitan dengan faktor resiko aterosklerosis dan prevalensi penyakit kardiovaskuler, dan penyakit vaskuler lainnya. ABI yang rendah berhubungan dengan faktor resiko kardiovaskuler, termasuk hipertensi, diabetes melitus, displipidemia, riwayat merokok, dan beberapa resiko penyakit penyakit vaskuler. Beberapa penelitian telah mengevaluasi hubungan ABI dengan faktor resiko penyakit kardiovaskuler dan berkaitan langsung dengan diabetes melitus. ABI sebagai ukuran dari tingkat keparahan aterosklerosis pada kaki yang juga merupakan indikator independen terhadap resiko terjadinya atherothrombotik pada pembuluh darah lainnya (Aboyans et al., 2012).

Hasil penelitian yang menggunakan ABI sebagai alat pengkajian sirkulasi pada pasien dengan kaki diabetik yang 
dilakukan oleh Hijriana, Suza, dan Ariani (2017) dan Lamkang (2017) setelah dilakukan exercise pada kaki pasien DM di dapatkan hasil terjadinya peningkatkan nilai ABI setelah dilakukan exercise. Hasil penelitian memperlihatakan bebarapa $\mathrm{ABI}$ memberikan kontribusi untuk pasien DM untuk mendeteksi komplikasi peripheral artery disease (PAD) pada pasien $\mathrm{DM}$ (Gibbs et al., 2013).

Chang et al. (2016) menyatakan dalam penelitianya yang menggunakan ABI sebagai cara untuk mendeteksi gangguan sirkulasi pada pasien DM, pengukuran $\mathrm{ABI}$ dapat digunakan untuk mendeteksi tingkat keparahan vaskulopati pada ekstremitas bawah pasien DM. Hasil penelitian yang dilakukan oleh Gibbs et al. (2013) didapatkan bahwa terdapat perbedaan yang signifikan antara $\mathrm{ABI}$ pasien sebelum dan sesudah dilakukan gerakan olah raga dimana, peningkatan $\mathrm{ABI}$ berkorelasi dengan penurunan $\mathrm{HbA}_{1} \mathrm{c}$, sistolik dan tekanan darah diastolik, namun efek olahraga terhadap perubahan ABI tetap signifikan.

Perawat mempunyai peranan yang besar dalam perawatan pasien dengan kateter, perawat sangat berperan dalam mencegah terjadinya infeksi pada pasien dengan mengindentifikasi faktor penyebab potensial yang dapat menyebabkan infeksi saluran kemih melalui pendekatan metodologi asuhan keperawatan, perawat melakukan pengkajian, menentukan diagnosa, menyusun rencana tindakan/ intervensi, melaksanakan rencana tindakan implementasi dan mengevaluasi tindakan asuhan keperawatan yang telah dilakukan. Data tentang ananlisa faktor penyebab infeksis saluran kemih akibat pemasangan kateter sangat diperlukan sebagai pertimbangan dalam melakukan asuhahan keperawatan yang tepat dan sebagai alat ukur penilaian keberhasilan asuhan keperawatan yang diberikan.

Hasil penelitian yang dilakukan oleh Yuan dan Yang (2017) perlu di tingkatkan kesadaaran dan pengetahuan tentang pencegahan komplikasi dari DM dengan cara dapat dilakukan oleh diri pasien sendri, yang berkolaborasi dengan perawat. Dari studi yang dilakukan Surme et al. (2016) menyatakan perawat tidak melakukan pengkajian dan perawatan yang optimal dikarenakan tidak adanya sebuah standar dan keberhasilan dalam sebuah perawatan pasien DM dimulai dengan pengukuran dan protocol yang objektif yang ada di rumah sakit.

Pengenalan dan perawatan dini pada pasien DM merupakan hal yang sangat penting untuk mencegah cedera lebih lanjut pada kaki pasien DM. Hal ini didukung dengan penelitian yang dilakuakan oleh Wade (2017) yang mendapatkan hasil dari penelitianya ada perubahan sosial yang dapat mengidentifikasi pasien DM sebelum terjadinya komplikasi sehingga perawat yang memberikan pelayanan kesehatan dapat mencegah komplikasi lanjut.

Hasil survei awal yang dilakukan peneliti mewawancarai perawat pelaksana di rumah sakit umum Mitra Medika Tanjung Mulia Medan di dapatkan data, perawat sudah melakukan perawatan pada pasien DM, tetapi perawat tidak melakukan pengkajian sirkulasi kaki pada pasien DM. Intervensi yang banyak dilakukan di ruangan seperti exercise yang berfungsi untuk mencegah kekakuan sendi, memperlancar sirkulasi, memperbaiki tonus otot, meningkatkan mobilisasi sendi dan perawatan luka pada pasien DM. Namun untuk pengkajian sirkulasi tidak dilakukan oleh perawat di ruangan dikarenakan pengetahuan perawat tentang pengkajian sirkulasi, fasilitas dan protokol pengkajian sirkulasi yang belum tersedia.

\section{Metode}

Desain penelitian menggunakan action reseach yang dilakukan satu siklus di Rumah Sakit Umum Mitra Medika Tajung Mulia Medan, dengan teknik purposive sampling. Penelitian dilakukan bulan Mei sampai bulan September 2018, instrumen yang digunakan pada penelitian adalah in-depth interview, focus grup 
discussion, self report. Sampel penelitian ini untuk in-depth interview menggunakan 3 partisipan perawat pelaksana, partisipan focus grup discussion terbagi dua kelompok yaitu kelompok 8 partisipan dari manajemen rumah sakit, kepala ruangan dan 8 partisipan dari perawat pelaksana, 45 perawat pelaksana untuk pengukuran self report, dengan teknik purposive sampling. Penelitian dilakukan bulan Mei sampai bulan September 2018. Kriteria sampel Partisipan in-depth interview, facus group discussion yang memiliki kriteria inklusi telah mengalami langsung situasi atau kejadian yang berkaitan dengan pengkajian sirkulasi pada pasien diabetes melitus di ruangan rawat inap rumah sakit umum Mitra Medika, mampu mengemukakan pendapat dan telah berpengalaman dalam bekerja di rumah sakit umum Mitra Medika, bersedia terlibat dalam kegiatan penelitian, bersedia untuk diwawancarai dan direkam aktifitasnya selama wawancara selama kegiatan penelitian berlangsung, 5) memberikan persetujuan untuk mempublikasikan hasil penelitian. Penelitian ini teah disetujui oleh Komite Etik Fakultas Keperawatan Universitas Sumatera Utara dengan 1518/VII/SP/2018 dan peneliti juga meminta persetujuan dari responden dengan informed consent.

Instrumen yang digunakan yaitu: 1)in-depth interview, 2)panduan focus group discussion (FGD), dan 3)kuesioner pengetahuan. Pengumpulan data kualitatif depth interview, facus group discussion menggunakan pertanyan: 1)apakah rumah sakit harus merumuskan protokol pengkajian srikulasi kaki pada pasien diabetes melitus atau SPO pengakajian tersbeut, mengapa? 2)strategi apakah yang dapat dilakukan untuk merumuskan protokol pengkajian sirkulasi kaki pada pasien diabetes melitus? 3)apakah pengkajian sirkulasi kaki pada pasien diabetes melitus harus diberikan oleh perawat di rumah sakit? 4)apa saja yang perlu diperhatikan dalam pemberian latihan pengkajian sirkulasi kaki pasien diabetes melitus tersebut? 5)apa saja kendala yang dihadapi dalam pengkajian sirkulasi kaki pada pasien diabetes mellitus? dan 6)hal apa saja yang di persiapkan untuk mendukung penerapan protokol pengkajian pengkajian sirkulasi kaki pada pasien diabetes melitus? 7)apa manfaat dalam hal pengkajian sirkulasi kaki pada pasien diabetes melitus?. Data kuantitatif menggunakan kuesioner pengetahuan perawat, dibuat oleh peneliti dan dikembangkan dengan menggunkan studi literatur, dan dimodifikasi sesuai dengan kebutuhan pada penelitian, terdiri dari 20 pertanyaan tentang pengetahuan pengkajian sirkulasi kaki pada pasien diabetes melitus yang terdiri dari dua jawaban YA atau TIDAK. Dimana jawaban YA oleh partisipan diberikan nilai $=1$, dan TIDAK diberikan nilai $=0$, jawaban partisipan dibagi dalam dua bagian yaitu: tahu dan tidak tahu. Apabila partisipan tahu maka nilainya 11-20, dan jika pasrtisipan penelitian tidak tahu maka nilanya $10-1$.

Semua alat instrumen dilakukan uji validitas instrumen dengan tiga orang expert. Hasil dari expert ketiga didapatkan Thasil content validity index (CVI) untuk instrument in-depth interview dengan nilai 0,83 , facus group discussion dengan nilai 0,85 , dan pengetahuan perawat dengan nilai 0,91. Hasil uji reliabilitas dengan jumlah responden 20 orang yang dilakukan di RSU Mitra Medika Amplas dilakukan analisa data menggunakan komputer dengan hasil cronbach alpha 0,96. Data penelitian ini dianalisis dengan dua cara yaitu analisis secara kualitatif dan kuantitatif. Analisis kualitatif dengan menggunakan konten analisis. Data kuantitatif dianalisis dengan menggunaknan deskriptif statistik. 
Hasil

Tabel 1.

Karakteristik Data Demografi Perawat $(\mathrm{n}=45)$

\begin{tabular}{|c|c|c|}
\hline Karakteristik & $\mathrm{f}$ & $\%$ \\
\hline \multicolumn{3}{|l|}{ Umur: } \\
\hline Remaja akhir 17 - 25 tahun & 30 & 66,70 \\
\hline Dewasa awal 26 - 35 tahun & 12 & 26,70 \\
\hline Dewasa Akhir 36- 45 tahun & 3 & 6,70 \\
\hline \multicolumn{3}{|l|}{ Jenis Kelamin: } \\
\hline Laki- laki & 15 & 33.33 \\
\hline Perempuan & 30 & 66,67 \\
\hline \multicolumn{3}{|l|}{ Pendidikan: } \\
\hline Ners & 25 & 56,66 \\
\hline D III Keperawatan & 20 & 44,44 \\
\hline \multicolumn{3}{|l|}{ Agama: } \\
\hline Islam & 30 & 66,66 \\
\hline Kristen & 10 & 22,22 \\
\hline Khatolik & 5 & 11,11 \\
\hline \multicolumn{3}{|l|}{ Lama Bekerja: } \\
\hline 1 tahun & 18 & 40,00 \\
\hline 2 tahun & 15 & 33,30 \\
\hline 3 tahun & 4 & 8,90 \\
\hline 4 tahun & 4 & 8,90 \\
\hline 5 tahun & 2 & 4,40 \\
\hline$>5$ tahun & 2 & 4,40 \\
\hline
\end{tabular}

bahwa perawat yang bertugas di ruang rawat inap rumah sakit umum Mitra Medika Tanjung Mulia Medan dengan jumlah 45 perawat dipimpin oleh 4 orang kepala ruangan dengan pendidikan terakhir Ners. Umur perawat yang bekerja adalah rata-rata (mean) umur partisipan yaitu: 34,6 dengan umur termuda adalah 21 tahun dan umur tertua adalah 39 tahun. Partisipan yang memiliki umur kategori 17-25 tahun yaitu sebanyak 30 orang $(66,70 \%)$. Tingkat pendidikan perawat yang bertugas adalah rata- rata memiliki latar belakang Diploma III Keperawatan (AKPER) sebanyak 20 orang $(44.44 \%)$ dan Ners sebanyak 25 orang perawat $(55.66 \%)$.

Siklus 1 tahap reconnaissance Kegiatan awal yang dilakukan oleh peneliti melalui metode observasi, wawancara individual in-depth interview, FGD, dan self report. Berdasarkan hasil observasi peneliti ditemukan permasalahan 1) di ruangan rawat inap rumah sakit tidak memiliki SOP untuk pengkajian sirkulasi melakukan pengkajian pada pasien DM tetapi perawat tidak melakukan pengkajian sirkkulasi kaki pada pasien DM, 3) perawat sudah melakukan intervensi keperawatan untuk meningkatkan sirkulasi kaki seperti senam kaki pada pasien DM tetapi tidak di lakukan pengkajian sirkulasi kaki, dan 4) perawatan luka pada pasien DM dilakukan oleh 2 orang perawat luka di rumah sakit perawat tidak mengetahui bentuk pengkajian sirkulasi terkait gejala yang dirasakan pada kaki pasien diabetes.

Hasil wawancara dengan 2 clinical instruktur dan 2 perawat di ruang rawat inap rumah sakit 1) selama perawat baru masuk 2 clinical instruktur tidak memberikan pengetahuan tentang pengkajian sirkulasi kaki pada pasien DM, tetapi 2 clinical instruktur mengajarkan tentang konsep kegawadaruratan, alur pelayanan pasien, alur rujukan dan lainlain, 2)perawat yang diruangan rawat inap belum melakukan pengkajian sirkulasi kaki khusus pada pasien DM, 3)perawatan 
pasien DM yang komplikasi seperti luka hanya dilakukan oleh perawat luka yang ada di rumah sakit, dan 4)clinical instruktur berperan dalam memberikan ilmu-ilmu baru kepada perawat yang ada di rumah sakit baik perawat baru maupun perawat yang lama. Hasil wawancara dengan 2 perawat pelaksana 1)selama merawat pasien DM perawat tidak melakukan pengkajian sirkulasi kaki pada pasien DM dikarekan perawat tidak tahu pengkajian sirkulasi tersebut, perawat hanya melnjutkan intervensi medis, tidak tersedianya SOP bagi perawat untuk mengkaji sirkulasi kaki pada pasien DM, perawatan khusus pasien DM dengan luka di rawat langsung oleh perawat luka di rumah sakit umum Mitra Medika Tanjung Mulia Medan, 2)protokol pengkajian sirkulasi kaki pada pasien DM tidak tersedia di ruangan rawat inap rumah sakit umum Mitra Medika Tanjung Mulia Medan, 3)fasilitas seperti alat yang dibutuhkan tidak tersedia di ruangan rawat inap rumah sakit umum Mitra Medika Tanjung Mulia Medan, 4)perawat mengatakan belum pernah mendapatkan sosialisi tentang pengkajian sirkulasi kaki di rumah sakit, dan 5)perawat bersedia mengikuti kegiatan apabila ada sosialiasi tentang pengkajian sirkulasi kaki pada pasien DM.

Hasil in-depth interview dengan melibatkan partisipannya adalah 3 orang perawat ditemukan 5 tema, yaitu: 1) penyedian SOP pengkajian sirkulasi kaki, 2) strategi pelaksanaan SPO tentang pengkajian sirkulasi kaki pada pasien DM,
3) manfaat penerapan protokol, hambatan penerapan SPO 5) dukungan terhadap pelaksanaan pengkajian sirkulasi, dan 11 kategori yaitu 1) SOP belum lengkap, 2) pengkajian tidak tersedia, 3) tahap menyusun SOP, 4) cara mempromosikan protokol, 5) manfaat bagi rumah sakit, 6) manfaat bagi perawat, 7) hambatan dari perawat, 8) hambatan dari rumah sakit, 9) dukungan dari pasien, 10) dukungan dari perawat, dan 11) dukungan dari pihak manajemen rumah sakit.

Berdasarkan hasil pengumpulan dengan menggunakan metode focus group discussion (FGD). FGD yang dilakukan terbagi 2 sesi, yaitu sesi manajemen rumah sakit, sesi perawat pelaksana ditemukan ditemukan 4 tema, yaitu: 1) strategi penerapan pengkajian sirkulasi kaki pada pasien DM, 2) keuntungan dalam penerapan pengkajian sirkulasi kaki DM, 3) hambatan dalam penerapan pengkajian sirkulasi kaki pada pasien DM, dan 4) teknik dan penerapan protokol pengkajian sirkulasi kaki pada pasien DM dan 10 kategori yaitu: 1) tahapan dalam menyusun SOP 2) cara mempromosikan protokol, 3) penyusunan SOP, 4) manfaat bagi rumah sakit, 5) manfaat bagi perawat, 6) manfaat bagi pasien, 7) hambatan dari manajemen rumah sakit, 8) hambatan dari perawat, 9) hambatan dari pasien, dan 10) dukungan dari manajemen rumah sakit.

Hasil pengukuran Pengetahuan perawat sebelum sosialisasi pengkajian sirkulasi kaki pada pasien diabetes melitus di Rumah Sakit Umum Mitra Medika Tanjung Mulia Medan:

Tabel 2.

Pengetahuan perawat sebelum sosialisasi pengkajian sirkulasi kaki pada pasien diabetes melitus $(n=45)$

\begin{tabular}{lccc}
\hline & Pengetahuan perawat & $\mathrm{f}$ & $\%$ \\
\hline $\begin{array}{l}\text { Tidak tahu } \\
\text { Tahu }\end{array}$ & & 6 & 13,33 \\
\hline \multicolumn{2}{c}{ Siklus 1 tahap planning meupakan } & sirkulasi kaki pada pasien DM di ruangan \\
langkah kedua dilaksanakan pada tanggal & rawat inap Rumah Sakit Umum Mitra \\
06 September 2018 dan bertujuan untuk & $\begin{array}{l}\text { Medika Tanjung Mulia Medan. Terkait } \\
\text { merumuskan }\end{array}$ & perencanaan dalam & kegiatan penelitian maka dilakukan: 1) \\
pengembangan protokol pengkajian & melakukan rencana pertemuan dengan tim
\end{tabular}


manajemen keperawatan 2) pembentukan tim pengembangan protokol pengkajain sirkulasi kaki pada pasien DM, 3) perumusan protokol pengkajian sirkulasi kaki pada pada pasien DM, dan 4) membuat perencanaan sosialisasi program penyusunan protokol pengkajian sirkulasi pada pasien diabetes melitus.

Siklus 1 tahap action dan observing Tahap ini dilaksanakan pada tanggal 10 September 2018 sampai dengan 20 September 2018. Tahap ini merupakan tahap pelaksanaan kegiatan yang telah direncanakan pada tahap planning. 1) rapat dengan manajemen rumah sakit, kegiatan ini dilaksanakan pada tanggal 10 September 2018, 2) pembentukan tim pengembangan protokol pengkajain sirkulasi kaki pada pasien DM dilaksanaakan tanggal 10 September 2018, 3) perumusan protokol pengkajian sirkulasi

Tabel 3

Pengetahuan perawat sesudah sosialisasi protokol pengkajian sirkulasi kaki pasien diabetes melitus $(n=45)$

\begin{tabular}{llll}
\hline \multicolumn{2}{c}{ Pengetahuan perawat } & \multicolumn{1}{c}{$\mathrm{f}$} & $\%$ \\
\hline Tidak tahu & & 0 & 0 \\
\hline Tahu & & 45 & 100 \\
\hline Hasil in-dept intervie dilakukan & $y a$, manfaatnya untuk kejelasan \\
pada 3 partisipan perawat pelaksana & perawatkan yahhh kayak legalitas kerja \\
didapatkan hasil 3 thema: 1) Manfaat & perawat di rumah sakit in (partisipan 1, L \\
penerapan protokol pengkajian sirkulasi & $13)$
\end{tabular}

kaki pada pasien DM, 2) Hambatan proses penerapan protokol pengkajian sirkulasi kaki pada pasien DM, 3) Dukungan penerapan protokol pengkajian sirkulasi kaki pada pasien DM.

1) Manfaat penerapan protokol pengkajian sirkulasi

Kegiatan in-dept interview yang dilakukan pada partisipan perawat pelaksana, didapatkan beberapa manfaat yang dirasakan setelah penerapan protokol pengkajian sirkulasi kaki pada pasien DM yaitu 1) manfaat protokol untuk rumah sakit seperti meningkatkan pelayanan meningkat kepuasan pasien bagi rumah sakit, dan 2) manfaat protokol untuk legalitas kerja perawat.

"Manfaat yang diperoleh dari penerapan protokol pengkajian sirkulasi kaki ini kaki pada pada pasien DM, sebanyak 4 kali dan dimulai sejak tanggal 10 sampai 17 September 2018 dan 4) sosialisasi pengkajian sirkulasi kaki di tingkat manajemen rumah sakit dan perawat rumah sakit umum Mitra Medika Tanjung Mulia Medan dilaksanakan tanggal 20 September 2018.

Siklus 1 tahap reflecting Tahap refleksi (reflecting) merupakan tahap akhir dari penelitian action research.

Pada tahap Tahap ini akan dilakukan dengan beberapa cara diantaranya menganalisis, mensintesis, menafsirkan, menjelaskan dan menarik kesimpulan serta memperluas kajian output yang telah disusun. Pada tahap reflecting kegiatan yang dilakukan peneliti adalah 1) evaluasi siklus 1 pada tanggal 25 September 2018, melakukan in-dept intervie, penyebaran

kuesioner pengetahuan perawat.

"Kalau menurut saya manfaat dari penerapan protokol dari pengkajian sirkulasi kaki ini yah pasien cepat sembuh dan dapat meningkatkan pelayanan kami disini" (partisipan 3, L 14)

2) Hambatan proses penerapan protokol pengkajian sirkulasi kaki pada pasien DM,

Penerapan protokol pengkajian sirkulasi kaki pada pasien DM selama dijalankan di ruang rawat inap mengalami hambatan yaitu, hambatan pada saat penerapan protok pengkajian yang masih baru sehingga membutuhkan motivasi bagi perawat untuk melakukannya, dan hambatan dari rumah sakit. Pernyataan 
tersebut sesuai dengan ungkapan partisipan berikut ini:

"Menurut saya ya kadang pas mau melakukanya lupa prosedurnya, baca lagi dan pas dinurse staion ingat ke ruangan pasien lupa lagi akhirnya dibaca sambil pemeriksaanya." (partisipan 2, L 49).

3) Dukungan penerapan protokol pengkajian sirkulasi kaki pada pasien DM.

Dukungan dalam menerapkan protokol pengkajian sirkulasi kaki pada pasien DM ini antara lain: 1) dukungan dari pasien, 2) dukungan dari perawat, dan 3) dukungan dari manajemen rumah sakit. Pendukung dari pasien seperti pasien lebih kooperatif, kepercayaan pasien kepada perawat lebih besar dari sebelum penerapan protokol, pasien lebih dekat dengan perawat, pasien antusias. Pendukung dari perawat pelaksana. Perawat semakin paham setelah mendapatkan sosialisasi tentang pengkajian sirkulasi kaki pada pasien DM oleh peneliti. Faktor pendukung dari manajemen rumah sakit antara lain berupa fasilitasi dari pihak rumah sakit berupa sarana - prasarana. Pernyataan tersebut sesuai dengan ungkapan beberapa partisipan berikut ini

"Menurut ku disini ya kalau sudah di setujui direktur rumah sakit akan memfasilitasi untuk melancarkan penerapan protokol ini" (partisipan 1, L 43).

"Yahhh perawa disini sudah ada yang bisa, setelah mendapatkan sosialisasi dari tim peneliti kami merasa lebih paham tentang pengkajian ini dan kami langsung coba ke pasien dan pasien jadi senang" (partisipan 2,L 35)

"Kalau menurut ku manfaat protokol yahhh dapat memberikan upaya kepuasan ke pasien, pasien jadi lebih nyaman di berikan layanan di rumah sakit ini"(partisipan 3, L 58).
Out put action reseach dalam penelitian ini telah tersusunnya protokol pengkajian sirkulasi kaki pada pasien DM. Protokol pengkajian sirkulasi kaki pada pasien DM ini mempermudah perawat dalam memberikan pelayanan kepada pasien khususnya tentang pengkajian sirkulasi kaki pada pasien DM, sehingga perawat terlatih untuk menerapkannya di lapangan.

\section{Pembahasan}

\section{Proses Pelaksanaan Action Research Reconnaissance}

Masalah yang ditemukan peneliti pada tahap reconnaissance adalah 1)perawat telah melakukan asuhan keperawatan kepada pasien DM namun pengkajian sirkulasi pada pasien DM belum dilakukan, 2)belum adanya protokol pengkajian sirkulasi kaki, 3)fasilitas yang dibutuhkan untuk pengkajian sirkulasi kaki pada pasien DM belum tersedia, dan 4) hasil pengukuran self report pengukuran pengetahuan tentang pengkajian sirkulasi yang peneliti lakukan di dapatkan 6 partisipan $(13,33 \%)$ tidak tahu tentang pengkajian sirkulasi kaki pada pasien DM, hal ini dikarenakan kurangnya terlaksananya pemaparan tentang pengkajian sirkulasi kaki, kurangnya minat partisipan dalam meningkatkan pengetahuan seperti tidak mengikiuti pelatihan, seminar, worskhop tentang kasus diabetes melitus, tidak tersedianya fasilitas yang dapat memberikan motivasi bagi perawat untuk mengetahui update ilmu baru. Hasil penelitian ini sejalan dengan penelitian yang di lakukan oleh Bilal et al (2018); Kumarasinghe et al (2017).

Permasalahan pada tahap reconnaissance sangat mempengaruhi pelaksanaan pengkajian sirkulasi kaki pada pasien diabetes melitus yang di rawat inap rumah sakit umum Mitra Medika Tanjung Mulia Medan. Dalam memberian asuhan keperawatan dan kualitas layanan yang akan diberikan kepada pasien sangat dipengaruhi oleh kesuksesan dalam 
melakukan pengkajian yang sesuai yang dapat dilakukan oleh perawat di ruangan rawat inap, dimana seorang perawat berperan dalam melakukan indetifikasi dan pencegahan dengan melakukan pengkajian yang sederhana pada pasien diabetes melitus dengan melakukan skrening kaki dapat menyelamatkan pasien dari komplikasi diabetes (Aalaa et al, 2012). Sejalan dengan penelitian yang dilakukan oleh Ren et al (2014) tentang pencegahan komplikasi pada pasien diabetes melitus didapatkan hasil bahwa perawat memiliki peran yang sangat besar untuk memberikan informasi bahwa dengan edukasi sangat efektif bagi perawat untuk mecegah komplikasi pada pasien DM.

$$
\text { Penelitian Wade }
$$

menyebutkan penting dilakukan identifikasi kaki pada pasien diabetes melitus karena sebagai langkah awal untuk mengetahui masalah yang sering terjadi pada pasein diabetes melitus. Menurut Canadian Association of Wound Care (WOUNDSCANADA, 2018) Kondisi kaki pada pasien diabetes melitus sering menyebabkan timbulnya komplikasi seperti luka kaki, penanganan yang segera akan mengurangi komplikasi dari diabetes melitus tersebut, sehingga dengan melakukan check up diabetic foot dapat mendeteksi resiko komplikasi dari diabetes melitus (Yuliani, Shulaeha, Yusri \& Yusuf, 2017). Hasil penelitian yang telah dilakukan peneliti, bahwa perawatan kaki pada pasien diabetes melitus tidak dilakukan dengan maksimal, perawat tidak melakukan pengkajian sirkulasi kaki di ruangan rawat inap rumah sakit umum Mitra Medika Tanjung Mulia Medan dikarenakan tidak tersedianya sarana untuk melakukan pengkajian tersebut.

Adapun kekurangan dari tahap ini adalah peneliti sulit dalam melakukan sharing dengan pejabat rumah sakit karena agenda mereka sudah dipadati oleh kegitan-kegitan organisasi, memberi pelayanan di rumah sakit.

\section{Planning}

Pada tahap planning peneliti menyusun rencana kegiatan yang akan dilakukan yang akan dilakukan sesuai dengan hasil yang ditemukan pada tahap reconnaissance. Terkait kegiatan penelitian maka dilakukan: 1) melakukan rencana pertemuan dengan tim manajemen keperawatan, 2) pembentukan tim pengembangan protokol pengkajain sirkulasi kaki pada pasien DM, 3) perumusan protokol pengkajian sirkulasi kaki pada pada pasien DM dan, 4) membuat perencanaan sosialisasi program penyusunan protokol pengkajian sirkulasi pada pasien DM. Tujuan dilakukannya planning adalah dapat melakukan pertemuan dengan tim penelitian di mana pertemuan ini untuk menyampaikan semua ide-ide, data yang di temukan untuk diselesaiakan bersama-sama dengan tim peneliti. Dinmohammadi, Peyrovi, dan Mehrdad (2013) pertemuan merupakan suatu kegiatan yang kompleks profesional dengan mendapatkan empat hal yaitu, interaksi, pembelajaran, perubahan dan adaptasi. Hasil penelitian yang dilakukan oleh Cooper et al (2016) dalam penelitianya mengatakan kegiatan pertemuan langsung dapat meningkatkan deteksi dini manajemen pasien safety di rumah sakit.

\section{Acting dan observasing}

Tahap ini merupakan tahap pelaksanaan kegiatan yang telah direncanakan pada tahap planning. Kegiatan yang dilakukan pada saat ini dengan melakukan rapat dengan manajemen rumah sakit, pembentukan tim pengembangan protokol pengkajain sirkulasi kaki pada pasien DM, perumusan protokol pengkajian sirkulasi kaki pada pada pasien DM, dan sosialisasi pengkajian sirkulasi kaki di tingkat manajemen rumah sakit dan perawat rumah sakit umum Mitra Medika Tanjung Mulia Medan.

Ada Kelemahan dari tahap ini adalah waktu pertemuan mengalami delay 
yang sangat lama sehingga pelaksanaanya tidak sesuai dengan waktu yang sudah ditentukan sesuai dengan tentative dan juga ide-ide dari yang disampaikan oleh beberapa peserta belum sesuai dengan yang kita harapkan masih berprinsip yang lama, serta dalam menentukan tentatif banyak yang menganggap bahwa ini sulit untuk dijalankan. Hasil observasi yang telah dilakukan terhadap TIM perumus didapatkan bahwa pelaksanaan proses pembentukan protokol pengkajian sirkualasi kaki pada pasien diabetes melitus telah dilaksanakan sesuai dengan aturan yang telah dibuat.

Seluruh rangkaian kegiatan perumusan protokol pengkajian sirkulasi kaki pada pasien diabetes melitus dengan melibatkan orang penting dalam pelayanan keperawatan. Tim sangat antusias dan rasa kepedulian yang tinggi oleh para partisipan serta terlihat saling berkolaborasi. Menurut College of Licensed Practical dengan kolaborasi yang baik, tim menghormati kepetingan, peran, dan tanggung jawab semua anggota tim dam memberikan asuhan keperawatan. Untuk menciptakan rasa kepedulian dan antusias para partisipan tentunya dibutuhkan satu pandangan dan saling percaya antara peneliti, partisipan dan pimpinan. Berdasarkan penjelasan diatas dapat disimpulkan bahwa pelaksanaan kolaborasi antar tim dalam layanan keperawatan diperlukan rasa saling percaya antar tim tersebut.

\section{Reflecting}

Kegiatan ini telah dilakukan melalui in-dept interview dan penyebaran kuesioner. Terdapat 3 tema yang diperoleh berdasarkan refleksi pada partisipan perawat pelaksana selama menerapkan protokol pengkajian sirkulasi kaki pada pasien DM yaitu 1)manfaat penerapan protokol pengkajian sirkulasi kaki pada pasien DM untuk stake holder. Hasil penelitian ini sejalan dengan penelitian yang dilakukan oleh Susyanti, Suza dan Ariani (2018) yang menghasilkan thema manfaat latihan fisik bagi pasien congestif heary failure. Hasil penelitian Salmah dan Susanto (2016) mengatakan pembuatan standar protokol upaya peningkatan pada mutu pelayanan medis dan akreditasi bagi rumah sakit. Hasil Penelitian yang dilakukan oleh Sales, Bernades, Gabriel, Brito, Moura, dan Zanetti (2017) mengatakan dengan penerapan SOP yang disedikan, perawat dabat melakukan tindakan yang dapat meningkatkan pelayanaan keperawatan yang diberikan. 2)hambatan dalam protokol pengkajian sirkulasi kaki pada pasien DM, dan 3)dukungan penerapan protokol pengkajian sirkulasi kaki pada pasien DM. Hambatan dalam penerapan protokol pengkajian sirkulasi pada pasien diabetes melitus menghasilkan sub tema: 1)hambatan dari perawat, dan 2)hambatan dari rumah sakit. kurangnya fasilitas pendukung dan waktu merupakan faktor utama yang menjadi penghambat dalam pembentukan protokol pengkajian sirkulasi kaki pada pasien diabetes melitus, dimana tanggung jawab yang amanahkan kepada partisipan di area klinis sangat banyak sehingga ada dari partisipan yang mencuricuri waktu dalam melakukan perumusan untuk mengerjakan tugasnya, serta referensi dari partisipan yang masih belum terupdate sehingga mengharuskan peneliti menjelaskan berulang kali terkait dengan perumusan protokol.

Hasil penelitian sejalan dengan penelitian yang dilakukan Stiyawan, Mansur dan Noor (2018) mengatakan ketidak patuhan partisipan dalam penerapan SOP di ruangan rawat jalan dikarenkan perawat tidak sepakat dengan SOP perawatan rawat jalan, partisipan lupa urutan SOP, lingkungan rumah sakit, fasilitas yang tidak mencukupi, serta dokumen tidak lengkap dari rumah sakit. Agar minimnya hambatan dalam melakukan SOP, maka dapat diberikan pemaparan materi, pelatihan dasar, pengawasan, melakukan pengembangan SOP baru (Aung, Nusalam \& Dewi, 2017). 
Kekurangan dalam tahap ini hampir sama dengan tahap-tahap lainnya yaitu waktu dalam melakukan atau merumuskan protokol banyak waktu yang meleset jauh dari perkiraan di saat planning, tim penelitian juga lagi terlibat dalam tim reakreditasi rumah sakit Mitra Medika di daerah lainya, sehingga peneliti hanya memliki waktu untuk merumuskan disaat partisipan istirahat makan siang dan pada saat partisipan tidak terlibat dalam kegiatan akreditasi.

\section{Simpulan dan Saran}

Output dari penelitian ini adalah tersusunnya protokol pengkajian sirkulasi kaki pada pasien DM. Hasil analisis dari penelitian ini didapatkan 4 tema yaitu: 1)Strategi penerapan protokol pengkajian sirkulasi kaki pada pasien diabetes melitus, 2)Manfaat dalam penerapan protokol pengkajian sirkulasi kaki pada pasien diabetes melitus, 3)Hambatan dalam penerapan protokol pengkajian sirkulasi kaki pada pasien diabetes melitus, dan 4)Teknik dan penerapan protokol pengkajian sirkulasi kaki pada pasien diabetes mellitus. Hasil penelitian ini juga berdampak pada peningkatan pengetahuan perawat tentang pengkajian sirkulasi kaki pada pasien DM juga semakin meningkat sebelum dan sesudah kegiatan penelitian dilakukan dari $86,66 \%$ menjadi $100 \%$.

\section{Daftar Pustaka}

Aboyans, V., Abraham, P., Diehm, C., McDermott, M, M., Preux, P., \& Jacobson, D, T. (2012). Measurement and interpretation of the ankle-bracial index: a scientific statement from the American Heart Association.

Circulation, $126: 2890=2909$.

DOI:10.1161/CIR.0b013e318276fbc $\mathrm{b}$

ADA (American Diabetes Association). 2016. Standards of Medical Care in Diabetes 2016. Diabetes Care,39;1

Aalaa, Malazy T.,, Sanjari, M., Peimani, M., Tehrani, M (2012). Nurses'role in diabetic foot prevention and care; a review. Iran. Journal of Diabetes \& Metabolic Disorders 2012,11:24http://www.jdmdonline.c om/content $/ 11 / 1 / 2$

Asif, M. (2014). The prevention and control the type-2 diabetes by changing

lifestyleanddietarypattern.https://ww w.ncbi.nlm.nih.gov/pmc/articles PMC3977406/

Azzolin, K, O., Goldmeier, S., Maggi, D. L.,\& Quadros, R. D. P. (2014). Ankle -bracial index: nurses strategy to cardiovasculer disease risk factors identification. Rev Esc Enferm USP; 48(2):221-5, doi: 10.1590/S008062342014000020004

Aung, S.S., Nusalam., Dewi, Y. S. (2017). Factor affecting the compliance of Myanmar nurse in performing standar precaution. JurnalNers. http://dx.doi.org/10.20473/jn.v12i1. 2294

Bilal, M., Haseb. A., Rehman, A., Arshad, H. M., Aslam, A., Godil, S., Qamar, M. A., Saif, N., Muhammad, H., Polani., Ayaz, A., Altamash, S., Ghazanfar., Zaki, M. Ghazali., Khurram, A., Malik, M., Ahmad, H. (2018) Knowledge, Attitudes, and Practices Among Nurses in Pakistan Towards Diabetic Foot. Cureus.DOI.10.7759/cureus.3001

Chang, C.C., Chen, M.Y., Shen, J.H, Lin, Y.B., Hsu, W.W., Lin, B.S. (2016). A Quantitative Real-Time Assesment of Buerger Exercise on Dorsal Foot Peripheral Skin Sirculation in Patient With Diabetes Foot. Journal of Medicine. Vol. 95 No. 46

Carville, K. (2012). Wound care manual (6th ed.). Perth: Silver Chain Foundation.Chaowalaksakun, P., Nantachaipan, P., Kunawiktikul, W., Panuthai, S., Kosachunhanun, N. Turale, S. (2016). Action Research: Development of a Diabetes Care Model ina CommunityHospital.https://tcithaijo. 
org/index.php/PRIJNR/article/view/2 391.

Cooper, M. R., Hongh. A., Beaudin. E., Dias. A., Kreser. S., Ingersol. C. P., Jakson. J. (2016). Implementing High Reliability for Patient Safety. Journal Nursing of Regulation. https://doi.org/10.1016/S21558256(16)31041-9.

Diabetes Care (2018). American Diabetes Association Standards of Medical Care in Diabetes 2018 Suplement 1. ADA. USA.ISSN 01495992.

Dinmohammadi, M., Peyrovi. H., Mehrdad. N. (2013). Concept analysis of professional socialization in nursing. Pubmed. doi: 10.1111/nuf.12006.

Gibbs, B. B., Dobrosielski, D. A., Althouse, A. D., \& Stewart, K. J. (2013). Effect of exercise training on ankle-brachial index in type 2 diabetes.Atherosclerosis.230:125-

130.Doi:10.1016/j.atherosclerosis.20 13.07.002.

Hingorani, A., Lamuraglia, G. M., Henke, P., Meissner, M. H., Loretz, L., Zinser, K. M., Murad, M. H. (2016). The management of diabetic foot: Aclinical practice guideline by the society for vascular surgery in collaboration with the american podiatric medical association and the society for vascular medicine. Journal of Vasular Surgery,63 (2),3S-21S.doi:

10.1016/j.jvs.2015.10.003.

Hijriana, I., Suza, DE, \& Ariani, A. (2017). Pengaruh latihan gerak sendi ekstremitas bawah terhadap nilai ankle brachial index (ABI) pada pasien DM tipe2. www. jurnal.unsyiah.ac.id/INJ/article/view/ 6452.

International Diabetes Ferderation. (2017). IDF diabetes atlas. International diabetes federation (SeventhEd). https://doi.org/10.1289/image.ehp.v1 $19 . \mathrm{i} 03$.
Johnson, M., Sanchez, P., Langdon, R., Manias, E., Leveet-Jones, T., Weidemann, G ., Aguilar. V. Everett, B.(2017). The impact of interruptions on medication errors in hospitals: an observational study of nurses. Pubmed. doi: 10.1111/jonm.12486.

Kumarasinghe, S. A., Hettiarachchi, P., Wasalathanthri, S. (2017). Nurses' knowledge on diabetic foot ulcer disease and their attitudes towards patients affected: A cross-sectional institution-based study. Journal of Clinical Nursing. DOI: 10.1111/jocn. 13917

Malik, M., Ahmad, H. (2018) Knowledge, Attitudes, and Practices Among Nurses in Pakistan Towards Diabetic Foot.

Cureus.DOI.10.7759/cureus.3001

Ren, M., Yang. C., Lin, D., Xiao, H. S., Mai, L., Guo, Y., Yan, L. (2014) Effect of Intensive Nursing Education on the Prevention of Diabetic Foot Ulceration Among Patients with High-Risk Diabetic Foot:a Follow-up Analysis. DIABETES TECHNOLOGY \& THERAPEUTICS. Volume 16, Number 9, 2014. DOI: 10.1089/dia.2014.0004

Riset Kesehatan Dasar (2018). Riset Kesehatan Dasar. Jakarta: Badan Litbangkes, Depkes RI, 2018.

Setyawan, H., Mansur., Noor, V. M. M. (2018). Dampak tidak patuh terhadap pelaksanaan SOP alur rawat jalan di rumah sakit X Malang. Jurnal Bisnis dan Manajemen, Volume 2, Nomor 1, Hal01-16DOI: http://dx.doi.org/10.25139/ekt.v2i1.6 41

Shrikhande, G, V., McKinsey, J, F. (2012). Diabetes and Peripheral Vascular Disease: Diagnosisand Management, Contemporary Diabetes, DOI 10.1007/978-1-62703-158-5_9.

Sales, C.B., Bernades, A., Gabriel, C. S., Brito, M. D.F., Moura, A. A. D \& Zanetti, A. C (2017) Standard 
Operational Protocols in professional nursing practice: use, weaknesses and potentialities. Brazil. REBEn:http://dx.doi.org/10.1590/00 34-7167-2016-0621

Salmah, S., Susanto (2016) Upaya Peningkatan Mutu Pelayanan Medis Pada Pembuatan Standar Prosedur Operasional Pelayanan Medis di Rumah Sakit Ibu dan Anak 'Aisyiyah Klaten. Jurnal Medicoeticolegal dan Manajemen Rumah Sakit, 5 (1): 73-76, Januari 2016: Website: http://journal.umy.ac.id/index.php/mr s. DOI: 10.18196/jmmr.5109

Surme, Y., Kartin, P. T., Curuk, G. N.M (2016). Knowledge and Practices of Nurses Regarding Wound Healing. Jurnal perianastesia nursing. Elsevier.

DOI: https://doi.org/10.1016/j.jopan.2016. 04.143

Suyanti, D., Suza, D. E., Ariani, Y. (2018). The development of physical activity protocol in patients with congestive heart failure in the hospital in patientwards. Belitung Nursing Journal. 2018 October;4(5):437-447.

Yusuf, S., Okuwa, M., Irwan, M., Rassa, S., Laitung, B., Thalib, A., ... Sugama, J. (2016). Prevalence and risk factor of diabetic foot ulcer in a regional hospital, Eastern Indonesia. Open Journal of Nursing, 6 (January), 1-10. Doi: 10.4236/ojn.2016.61001.

Yuliani. K., Sulaeha., Sukri. S., Yusuf. S. (2017) Check up deteksi dini risiko luka kaki diabetes pada pasien diabetes mellitus di Makassar uji sensitifitas dan spesifisitas. Hasanuddin Student Journal. Vol. 1(1): 62-65. ISSN: 2579-7859, EISSN: 2579-7867.

Yuan, C \& Yang, D. (2017).Prevention of diabetic complications among the
elderly.Thesis Centeria University of apllaide sciences.

Wade, L. (2017). Development of Assessment and Screening Tool to Assist with Prevention and Identification of Charcot Foot in Type 2 Diabetics. www.symbiosisonlinepublishing.co $\underline{\mathrm{m}}$

Woundscanad. (2018) Best Practice Recommendations for the Prevention and Management of Diabetic Foot Ulcers.

WoundsCANADA.https://www.wou ndscanada.ca 
Jurnal Perawat Indonesia, Volume 3 No 2, Hal 145-158, Agustus 2019 Persatuan Perawat Nasional Indonesia Jawa Tengah 